\title{
Interventions to prevent anastomotic leak after esophageal surgery: a systematic review and meta-analysis
}

Emma J. M. Grigor ${ }^{1,2,3^{*}}$ C, Suha Kaaki ${ }^{1,3}$, Dean A. Fergusson ${ }^{2}$, Donna E. Maziak ${ }^{1,2}$ and Andrew J. E. Seely ${ }^{1,2}$

\begin{abstract}
Background: Anastomotic leakage $(\mathrm{AL})$ is a common and serious complication following esophagectomy. We aimed to provide an up-to-date review and critical appraisal of the efficacy and safety of all previous interventions aiming to reduce $\mathrm{AL}$ risk.
\end{abstract}

Methods: We searched MEDLINE and Embase from 1946 to January 2019 for randomized controlled trials (RCTs) evaluating interventions to minimize esophagogastric AL. Pooled risk ratios (RR) for AL were obtained using a random effects model.

Results: Two reviewers screened 441 abstracts and identified 17 RCTs eligible for inclusion; 11 studies were metaanalyzed. Omentoplasty significantly reduced the risk of AL by $78 \%$ [RR: $0.22 ; 95 \%$ Cl: $0.10,0.50]$ compared to conventional anastomosis ( 3 studies, $n=611$ patients). Early removal of $N G$ tube significantly reduced the risk of $A L$ by $62 \%$ [RR: $0.38 ; 95 \%$ Cl: $0.02,0.65$ ] compared to prolonged NG tube removal ( 2 studies, $n=293$ patients); Stapled anastomosis did not significantly reduce the risk of AL [RR: $0.92 ; 95 \% \mathrm{Cl}: 0.45,1.87$ ] compared to hand-sewn anastomosis ( 6 studies, $n=1454$ patients). The quality of evidence was high for omentoplasty (vs. conventional anastomosis), moderate for early NG tube removal (vs. prolonged NG tube removal), and very low for stapled anastomosis (vs. hand-sewn anastomosis).

Conclusions: This is the first meta-analysis to summarize the graded quality of evidence for all RCT interventions designed to reduce the risk of AL following esophagectomy. Our findings demonstrated that omentoplasty significantly reduced the risk of AL with a high quality of evidence. Although early NG tube removal significantly reduced AL risk, there is a need for further research to strengthen the quality of evidence for this finding. Evidence profiles presented in our review may help inform the development of future clinical practice recommendations.

Systematic review registration: CRD42019127181.

Keywords: Anastomotic leakage, Esophagectomy, Cancer, Carcinoma, Intervention, Adverse events

\section{Background}

Esophagectomy is a critical component of curative treatment for esophageal cancer. This procedure carries a significant risk for certain adverse events among patients

\footnotetext{
*Correspondence: egrig010@uottawa.ca

${ }^{1}$ Department of Surgery, Division of Thoracic Surgery, The Ottawa Hospital, 501 Smyth Road, PO Box 201B, Ottawa, ON K1H 8L6, Canada Full list of author information is available at the end of the article
}

undergoing esophagectomy. One of the most serious adverse events associated with esophagectomy is anastomotic leakage $(\mathrm{AL})$, which involves the leak of gastric fluid outside of the anastomosis postoperatively [1]. The presence of AL, with the rates being shown to occur up to $50 \%$ in some studies, is a potentially serious adverse event for patients and it has previously been significantly associated with prolonged length of stay, the formation of strictures, and increased morbidity and mortality $[2,3]$. 
There have been several interventions conducted previously that aimed to prevent $A L$, ranging from surgical interventions to more conservative measures. Omentoplasty is a standardized surgical technique that harnesses a pedicle flap from the omentum (a layer of abdominal fat that is attached to the greater curvature of the stomach) to cover or wrap around the anastomosis site. The omental flap, secured in place with hand-sewn sutures, is well perfused by vascularity from the preserved left gastro-epiploic artery [4-6]. The improved vascularity and delivery of oxygenated and nutrientrich blood to the surgical site from the omental flap is thought to enhance wound healing [7]. Omentoplasty has demonstrated promising findings in previous randomized controlled trial (RCT) studies to prevent AL after esophagectomy, which has been summarized in two previous meta-analyses conducted by Chen et al. 2014 and Yuan et al. 2019 [8, 9]. Another intervention investigated in previous studies includes the early removal of the nasogastric (NG) tube after esophagectomy. It is believed that increased strain on the wall of the esophagus during anastomotic site dilation postoperatively may worsen vascular perfusion of the surgical site and lead to increased risk for anastomotic leakage. NG decompression, which reduces dilation of the esophagus tissue, may serve to reduce the risk for an anastomotic leak [10]. Weijs et al. 2017 meta-analyzed previous controlled trials that showed the early removal of NG tubes (no NG tube or removal within 1-2 postoperative days) did not significantly reduce incidence of AL compared to prolonged NG tube removal (6 to 10 postoperative days) after esophagectomy [11]. Additional studies have explored the effect of different anastomotic surgical techniques on the incidence AL [10]. A meta-analysis by Beitler et al. 1998 compared the use of stapled compared to hand-sewn anastomoses and demonstrated no significant difference [12]. An up-to-date summary of the literature comparing previously explored interventions is warranted.

There is a need for an up-to-date review comparing the efficacy of all previous interventions designed to prevent AL after esophagectomy. A systematic approach to grading the quality, which can be accomplished using frameworks such as GRADE (Grading of Recommendations, Assessment, Development, and Evaluations), is essential to guide clinical practice recommendations [13]. Properly conducted RCT studies are the gold standard for evaluating the effect of an intervention [15]. Therefore, the present meta-analysis aimed to provide a comprehensive and up-to-date summary of all previous interventional RCTs that sought to reduce esophagogastric AL rates after esophagectomy, as well as provide systematic grading of quality among meta-analyzed interventions.

\section{Methods}

This systematic review and meta-analysis was conducted according to the Preferred Reporting Items for Systematic Reviews and Meta-analyses guidelines (PRISMA checklist) [14]. The protocol is available in the International Prospective Register of Systematic Reviews (CRD42019127181).

\section{Search strategy}

MEDLINE (OVID interface, including In-process and Epub Ahead of Print) and Embase (OVID interface) databases were searched from 1946 to February 2019 (Additional file 1). The literature search results were uploaded and reviewed using Covidence Software (Covidence, Melbourne, Australia).

\section{Selection criteria}

Potentially eligible studies were screened by title and abstract (stage 1) followed by full-text article screening to assess full eligibility (stage 2). Literature search results and full-text articles that met full eligibility criteria were reviewed independently and in duplicate by two reviewers. Any disagreement was resolved through discussion with a third reviewer. The reasons for exclusion were recorded. RCT studies that evaluated any intervention aiming to reduce the risk of AL after esophagectomy were included with no restriction on language. Only RCT studies that reported AL, our primary outcome, were included Articles including reviews, editorials, preclinical studies, observational studies, and abstracts were excluded.

\section{Outcome justification and prioritization}

Our primary outcome AL was defined as the presence of extraluminal collections of air or contrast, excess bilestained fluid on drainage, or a combination [15]. Secondary outcomes of interest included anastomotic stricture, mortality, and length of stay in hospital postoperatively.

\section{Data extraction}

Patient and study characteristics, intervention details, and outcomes of interest were extracted from RCT studies that met full eligiblity. Two reviewers performed data extraction independently and in duplicate. Any disagreements were resolved by a third reviewer. The patient characteristics recorded included the total number of patients investigated (intervention and control groups), the mean age of participants $( \pm \mathrm{SD})$, and the ratio of males-to-females. The study characteristics recorded included the first author name, year of publication, study country of origin, the prevalence of AL (\%), and the use of neoadjuvant therapy (e.g. radiation, chemotherapy), the mean $( \pm \mathrm{SD})$ or median (IQR) length of 
stay in days, and the mean follow-up in months $( \pm S D)$. The intervention details recorded included the intervention type (e.g. omentoplasty, stapled vs. hand-sewn anastomosis, early NG tube removal, other), diagnostic modality used for anastomosis (e.g. gastrografin contrast), medical management used (e.g. antibiotics), endoscopic management used (e.g. NG tube use), the surgical management used (e.g. reoperation) and the surgical approach for esophagogastric anastomosis (e.g. cervical or thoracic anastomosis).

\section{Summary measures and synthesis of results}

Open Meta-Analyst (Open-source, USA) was used to generate heterogeneity measurements and effect estimates for risk ratios (RR) and weighted mean differences (WMD). The pooled (RR) estimates and pooled weighted mean difference (WMD) estimates (evaluating the difference in the length of stay between intervention and control groups) were determined using dichotomous and continuous DerSimonian and Laird random effects models, respectively [16]. Pooled RR and WMD estimates were stratified according to intervention type. The heterogeneity of pooled effect sizes was assessed using the Cochrane $\mathrm{I}^{2}$ statistic and the level was approximated using the following thresholds: 0-40\% (low heterogeneity), 30-60\% (moderate heterogeneity), 50-90\% (substantial heterogeneity) and 75-100\% (considerable heterogeneity) [16]. Studies that did not report the mean $( \pm S D)$ length of stay were excluded from the pooled WMD estimate. The statistical significance was evaluated using a $95 \%$ confidence interval (CI). Subgroup analysis of $\mathrm{AL}$ was performed according to the type of disease (e.g. esophageal cancer), age ( $\leq$ or $>18$ years old), type of surgery (cervical vs. thoracic anastomosis), and use of induction therapy or neoadjuvant therapy.

A pooled RR estimate of greater than one represented a higher risk of AL, stricture, or and mortality; a value less than one demonstrated a lower risk. A pooled WMD estimate of less than zero represented a shorter length of stay in the intervention group (vs. control group); a value greater than zero represented a longer length of stay.

\section{Risk of bias}

The Cochrane revised risk of bias tool for randomized trials was used to evaluate the individual risk of bias for studies reviewed [13]. Within each risk of bias domain, a series of questions ('signaling questions') were chosen to elicit information about features of the trial that were deemed to be relevant to the risk of bias. Publication bias was included in the assessment. Judgement was classified as 'low', 'high', or as having 'some concerns' [13]. Meta-bias (risk of bias across studies) was summarized by pooling the individual study risk of bias for each risk of bias domain.

\section{Grading of recommendations, assessment, development, and evaluations}

The quality for each intervention effect was graded by using a systematic and comprehensive approach known as GRADE [13]. GRADE provides a reproducible and transparent framework for grading the quality of evidence or certainty in the evidence. The quality of evidence reflects the extent to which we are confident that an estimate of the effect is correct. High grade of evidence means the true estimate lies close to the estimate of effect; moderate grade means that the true effect is likely to be close to the estimate of the effect; low grade means that the effect estimate may substantially differ from the true estimate of the effect; very low grade means we have little confidence in the effect estimate [13].

\section{Results}

The systematic searches returned a total of 731 citations. Following deduplication, 441 citations were identified. Of the 441 citations, 73 full manuscripts were identified as potentially eligible with a total of 17 RCTs meeting our eligibility criteria $(n=3,157$ patients). Eleven studies were included in our meta-analysis as shown in our PRISMA flow diagram (Fig. 1).

Studies were published between 1996 and 2019, with sample sizes ranging from 32 to 516 participants. The mean age of participants was similar across studies ranging from 50.8 to 67.5 years old. Follow-up periods were highly variable ranging from 3 months to 3 years. Most studies were performed in China (5 studies, 19\%), India (4 studies, 24\%), Japan (3 studies, 18\%), or other (5 studies [Iran, Hong Kong, Thailand, Netherlands, France], 29\%). The proportion of male participants was higher than female participants in all studies except one. The incidence of AL ranged from 1.4 to $17 \%$. The patient characteristics of the included studies are provided in Table 1.

Seven studies (41\%) investigated stapled (vs. hand sewn) anastomosis, three studies (18\%) investigated omentoplasty (vs. conventional stapled or hand-sewn anastomosis), three studies (18\%) investigated early NG tube removal (postop day 1 or 2 days) or no NG tube (vs. conventional 7 to 10 days to NG tube removal), two studies (12\%) that investigated subtotal gastric resection (vs. slender gastric tube) reconstruction, one study (6\%) investigated valvuloplasty (vs. stapled anastomosis), and one study $(6 \%)$ that compared end-to-end (vs. end-toside) anastomosis. Sixteen studies (94\%) used contrast to diagnose AL and six studies (35\%) used additional endoscopy and/or chest tube or drain output. Seven studies (41\%) administered medical management, three studies 


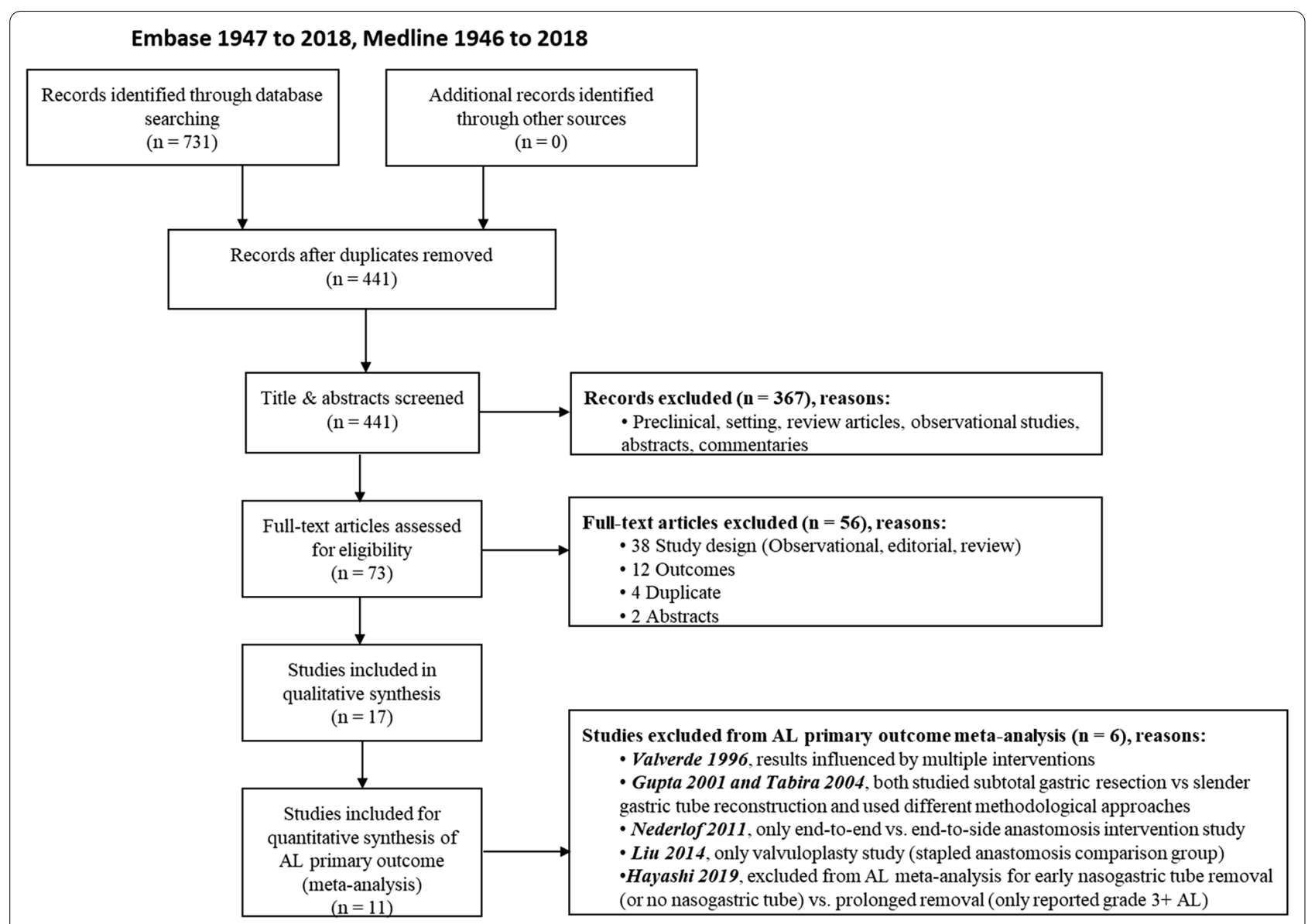

Fig. 1 PRISMA flow diagram summarizing screening and selection of eligible studies

(18\%) administered surgical management, and two studies (12\%) administered endoscopic management for the treatment of AL. The length of stay in hospital postoperatively varied from 10.7 to 29.4 days. The study intervention characteristics are outlined in Table 2.

\section{Primary outcome \\ Anastomotic leak}

The pooled results for eleven meta-analyzed studies are summarized in Fig. 2 and the descriptive results for single RCT interventions are summarized in Additional file 1: Table S2. Esophagectomy patients that received stapled esophagogastric anastomosis demonstrated a similar risk of AL (RR: 0.92; 95\% CI: 0.45, 1.87; $\mathrm{I}^{2} 40.1 \%$ ) compared to hand-sewn that was not significantly different (6 studies, $\mathrm{n}=1454$ patients). Esophagectomy patients that received omentoplasty had a $78 \%$ reduction in risk of AL (RR: 0.22; 95\% CI: 0.10, 0.50; $\mathrm{I}^{2} 0 \%$ ) compared to hand-sewn or stapled anastomosis alone that was significant (3 studies, $\mathrm{n}=611$ patients). Esophagectomy patients with early NG tube removal (or no NG tube) demonstrated a $62 \%$ reduction in risk of AL (RR: 0.38; 95\% CI: 0.02, 0.65; $\mathrm{I}^{2}$
$0 \%$ compared to prolonged NG tube removal that was significant ( 2 studies, $\mathrm{n}=293$ patients).

The pooled RR estimates for AL were subgrouped according to the site of esophagogastric anastomosis (Table 3). The pooled RR estimate for AL in the cervical esophagogastric anastomosis subgroup ( 2 studies, RR: 0.23 ; $95 \%$ CI: $0.069,0.788 ; \mathrm{I}^{2} 0 \%$ ) was not significantly different compared to the pooled RR for thoracic esophagogastric anastomosis subgroup (2 studies, RR: 0.19; 95\% CI: $\left.0.034,1.032 ; \mathrm{I}^{2} 0 \%\right)$. The pooled RR estimates for AL were also subgrouped according to stapled or hand-sewn esophagogastric anastomosis (Additional file 1: Table S3). The RR estimate for AL in the stapled esophagogastric anastomosis subgroup ( 1 study, $\mathrm{n}=194$ patients, RR: 0.214; 95\% CI: $0.064,0.722$ ) was not significantly different compared to the pooled RR estimate in the handsewn esophagogastric anastomosis subgroup (2 studies, $\mathrm{n}=417$ patients, RR: 0.264; 95\% CI: 0.089, 0.789). Due to a lack of reporting of $\mathrm{AL}$ according to neoadjuvant therapy type (radiation and/or chemotherapy), it was not possible to perform this planned subgroup analysis. 
Table 1 Characteristics of the included studies and participants studies

\begin{tabular}{|c|c|c|c|c|c|c|c|c|}
\hline $\begin{array}{l}\text { First author } \\
\text { (year) }\end{array}$ & Country & $\begin{array}{l}\text { Total } \\
\text { participants } \\
\text { (N) }\end{array}$ & $\begin{array}{l}\text { Total } \\
\text { participants } \\
\text { in intervention } \\
\text { groups }(\mathrm{n})\end{array}$ & $\begin{array}{l}\text { Prevalence } \\
\text { AL (\%) }\end{array}$ & $\begin{array}{l}\text { Male-to-female } \\
\text { ratio evaluated } \\
(\mathrm{T}, \mathrm{I}, \mathrm{C})\end{array}$ & $\begin{array}{l}\text { Age, years }(y) \\
\text { Mean } \pm S D\end{array}$ & $\begin{array}{l}\text { Neoadjuvant } \\
\text { therapy }\end{array}$ & $\begin{array}{l}\text { Follow-up, } \\
\text { months (mo, wk, } \\
\text { or y) } \\
\text { Mean } \pm \text { SD }\end{array}$ \\
\hline Bhat 2006 [6] & India & 194 & 97 & 8.8 & $\mathrm{~T}: 3: 1.8$ & T: 52.5 & $\begin{array}{l}\text { Excluded } \\
\text { patients with } \\
\text { previous neo- } \\
\text { adjuvant Tx }\end{array}$ & $\begin{array}{l}\text { F/U every 3-mo } \\
\text { for } 3 \text { y postop } \\
\text { every 4- to 6-mo } \\
\text { postop }\end{array}$ \\
\hline Dai 2011 [5] & China & 253 & 127 & 3.1 & $\mathrm{~T}: 4: 01$ & $\mathrm{~T}: 63.5$ & $\begin{array}{l}\text { Excluded } \\
\text { patients with } \\
\text { previous neo- } \\
\text { adjuvant Tx }\end{array}$ & *22 mo (3-52 mo) \\
\hline Daryaei 2008 [19] & Iran & 40 & 18 & 15 & $N R$ & $\mathrm{~T}: 58.4 \pm 10.3$ & $N P$ & NP \\
\hline Gupta 2001 [20] & India & 100 & 48 & 12 & $\begin{array}{l}\text { I: } 0.8: 1 \\
\text { C: } 0.7: 1\end{array}$ & $\begin{array}{l}\text { I: } 51.3 \pm 13.0 \\
\text { C: } 50.8 \pm 13.2\end{array}$ & $\begin{array}{l}\text { Rad } \pm \text { Chemo: } \\
\text { 22/100 and } \\
\text { Chemo alone: } \\
\text { 56/100 }\end{array}$ & 3 mo or more \\
\hline Hayashi 2019 [21] & Japan & 71 & 34 & 5.6 & $\mathrm{~T}: 6: 8$ & T: 63.04 & $\mathrm{NP}$ & NP \\
\hline Law 1997 [22] & Hong Kong & 122 & 61 & 3.3 & $\begin{array}{l}\text { l: } 7.7: 1 \\
\text { C: } 6.6: 1\end{array}$ & $\begin{array}{l}\text { l: } 64 \pm 1.2 \\
\text { C: } 63 \pm 1.0\end{array}$ & NP & $\begin{array}{l}20 \text { (SD 2.2) mo } \\
\text { hand-sewn } \\
\text { and } 19(2.2) \text { mo } \\
\text { stapled group } \\
(p=N S)\end{array}$ \\
\hline Liu 2014 [7] & China & 378 & 188 & 4.2 & $\mathrm{~T}: 3: 01$ & $\mathrm{~T}: 64$ & $\begin{array}{l}\text { Excluded } \\
\text { patients with } \\
\text { previous neo- } \\
\text { adjuvant Tx }\end{array}$ & NP \\
\hline Liu 2015 [23] & China & 432 & 219 & 5 & $\begin{array}{l}\text { I: } 3: 1 \\
C: 3: 1\end{array}$ & $\begin{array}{l}\text { l: } 62 \pm 8 \\
C: 61 \pm 9\end{array}$ & $\begin{array}{l}\text { Rad + chemo: } \\
\text { 64/478 }\end{array}$ & $\begin{array}{l}17.8 \text { (3.2) mo hand- } \\
\text { sewn and } 18.3 \\
\text { (3.4) mo stapled }\end{array}$ \\
\hline $\begin{array}{l}\text { Luechakiettisak } \\
2008[24]\end{array}$ & Thailand & 104 & 52 & 4.8 & $\begin{array}{l}\text { I: } 4.8: 1 \\
\text { C: } 5.6: 1\end{array}$ & $\begin{array}{l}\text { I: } 63.6 \\
\text { C: } 62.0\end{array}$ & NP & NP \\
\hline Mistry 2012 [25] & India & 253 & 127 & 3.1 & $\mathrm{~T}: 2.1: 1$ & $\begin{array}{l}\text { I: } 53.4 \\
\text { C: } 56.7\end{array}$ & $\begin{array}{l}\text { Rad } \pm \text { Chemo: } \\
\text { 2/150 and } \\
\text { Chemo alone: } \\
\text { 72/150 }\end{array}$ & NP \\
\hline $\begin{array}{l}\text { Nederlof } 2011 \\
\text { [26] }\end{array}$ & Netherlands & 128 & 64 & 31 & $\begin{array}{l}\text { I: } 2: 1 \\
C: 7: 1\end{array}$ & $\begin{array}{l}\text { l: } 60 \\
C: 63\end{array}$ & $\begin{array}{l}\text { Rad + Chemo: } \\
\text { 27/64 and } \\
\text { Chemo alone: } \\
\text { 17/64 }\end{array}$ & $\begin{array}{l}\text { 3- or 6-wk outpa- } \\
\text { tient visit. } 3 \text { mo } \\
\text { first y postop. } \\
\text { Every } 4 \text { mo sec- } \\
\text { ond y postop }\end{array}$ \\
\hline $\begin{array}{l}\text { Okuyama } 2007 \\
\text { [27] }\end{array}$ & Japan & 32 & 14 & 12 & $\begin{array}{l}\text { I: } 13: 1 \\
\text { C: } 16: 2\end{array}$ & $\begin{array}{l}\text { I: } 63.6 \\
\text { C: } 64.3\end{array}$ & $\begin{array}{l}\text { Excluded } \\
\text { patients with } \\
\text { previous neo- } \\
\text { adjuvant Tx }\end{array}$ & $5 y$ \\
\hline Saluja 2012 [28] & India & 174 & 87 & 17 & $\begin{array}{l}\text { I: } 2.3: 1 \\
\text { C: } 1.6: 1\end{array}$ & $\begin{array}{l}\text { I: } 51.4 \pm 12 \\
\text { C: } 50.9 \pm 14\end{array}$ & $\begin{array}{l}\text { Rad + Chemo: } \\
\text { 107/174 }\end{array}$ & NP \\
\hline Zhang 2010 [29] & China & 516 & 272 & 1.4 & $\begin{array}{l}\text { I: } 1.4: 1 \\
\text { C: } 1.4: 1\end{array}$ & $\begin{array}{l}\text { l: } 59 \pm 1.2 \\
\text { C: } 60 \pm 1.3\end{array}$ & $\begin{array}{l}\text { Excluded } \\
\text { patients with } \\
\text { previous neo- } \\
\text { adjuvant Tx }\end{array}$ & $12 \mathrm{mo}$ \\
\hline Zheng 2013 [4] & China & 164 & 82 & 8.5 & $\begin{array}{l}\text { I: } 1.6: 1 \\
\text { C: } 1.4: 1\end{array}$ & $\begin{array}{l}\text { l: } 67.5 \pm 11.2 \\
\text { C: } 65.7 \pm 9.4\end{array}$ & $\begin{array}{l}\text { None of the } \\
\text { patients } \\
\text { received } \\
\text { chemotherapy } \\
\text { or radiotherapy } \\
\text { pre-op }\end{array}$ & $3 y$ \\
\hline Tabira 2004 [30] & Japan & 44 & 22 & 14 & $\begin{array}{l}\text { I: } 6.3: 1 \\
\text { C: } 10: 1\end{array}$ & $\begin{array}{l}\text { l: } 64 \pm 8 \\
C: 60 \pm 8\end{array}$ & NP & NP \\
\hline $\begin{array}{l}\text { Valverde } 1996 \\
\text { [31] }\end{array}$ & France & 152 & 78 & 16 & $\begin{array}{l}\text { I: } 9.6: 1 \\
\text { C: } 10.1: 1\end{array}$ & $\begin{array}{l}\text { l: } 59 \pm 9 \\
C: 59 \pm 10\end{array}$ & NP & NP \\
\hline
\end{tabular}


Table 1 (continued)

C control, Chemo chemotherapy, I intervention, mo months, NP not provided, pre-op pre-operatively, postop postoperatively, Rad radiation, SD standard deviation, $T x$ therapy, wk weeks, $Y$ years

*Median (range)

\section{Secondary outcomes \\ Anastomotic stricture}

Esophagectomy patients that received stapled esophagogastric anastomosis had a twofold increased risk of stricture (RR: $2.11 ; 95 \% \mathrm{CI}: 1.36,3.26 ; \mathrm{I}^{2} 35.0 \%$ ) compared to hand-sewn (6 studies, $\mathrm{n}=1380$ patients). Esophagectomy patients that received omentoplasty had an $8 \%$ lower risk of stricture (RR: 0.92; 95\% CI: 0.33, 2.57; $\mathrm{I}^{2} 65.1 \%$ ) that was not significantly different compared to conventional anastomosis (3 studies, $n=613$ patients). The pooled results are summarized in Fig. 3.

\section{Mortality rate}

Esophagectomy patients that received stapled esophagogastric anastomosis had no statistically significant difference in risk of mortality (RR: 1.22; 95\% CI: 0.75, 1.98; $\left.\mathrm{I}^{2} 0 \%\right)$ compared to hand-sewn esophagogastric anastomosis (6 studies, $\mathrm{n}=1363$ patients). Esophagectomy patients that received omentoplasty had a $20 \%$ lower risk of mortality (RR: 0.80; 95\% CI: 0.32, 2.0; $\mathrm{I}^{2} 0 \%$ ) compared to conventional anastomosis (3 studies, $\mathrm{n}=736$ patients). Esophagectomy patients with early NG tube removal (or no NG tube) demonstrated no statistically significant difference in risk of mortality (RR: 0.90; 95\% CI: 0.317, $\left.2.55 ; \mathrm{I}^{2} 0 \%\right)$ compared to prolonged NG tube removal (2 studies, $n=190$ patients). The pooled results are summarized in Fig. 4.

\section{Length of stay}

The pooled weighted mean difference (WMD) for length of stay in hospital postoperatively was determined based on statistical comparison of the mean $( \pm S D)$ length of stay reported for intervention and control groups among the included studies. Esophagectomy patients that received stapled anastomosis had a 1.1-day longer length of stay in hospital [95\% CI: - 0.01, 2.2; $\mathrm{I}^{2} 0 \%$ ] compared to hand-sewn anastomosis that was not significantly different ( 2 studies, $\mathrm{n}=606$ patients). Esophagectomy patients that received omentoplasty had a 2.1-day shorter length of stay in hospital (WMD: -2.1 ; 95\% CI: -3.6 , - 0.6; $\left.\mathrm{I}^{2} 0 \%\right)$ that was statistically significant compared to stapled or hand-sewn anastomosis alone (2 studies, $\mathrm{n}=417$ patients). Esophagectomy patients with early NG tube removal (or no NG tube) had a 3.2-day shorter length of stay in hospital (WMD: -3.2 ; 95\% CI: $-6.5,0.2$; $\mathrm{I}^{2} 0 \%$ ) compared to prolonged NG tube removal that was not significantly different ( 2 studies, $\mathrm{n}=111$ patients). Mistry et al. 2012 was excluded from the pooled WMD estimate as only median (IQR) was reported for length of stay; early NG tube removal (or no NG tube) and prolonged NG tube removal groups each had a median length of stay of 12 days with similar variability of 9-17 and 10-17 days, respectively $(\mathrm{P}=0.18)$ [17].

\section{Risk of bias}

Seven (64\%) meta-analyzed studies did not report whether the allocation of participants was concealed. Nine (82\%) meta-analyzed studies lacked any details surrounding blinding of outcome assessment was blinded. Ten (91\%) meta-analyzed studies lacked reporting of outcome assessment blinding. The risk of bias across studies is summarized in Fig. 5 (Individual study risk of bias is summarized in Additional file 1: Table S4).

\section{Grade}

There was a high quality of evidence for $\mathrm{AL}$ in the omentoplasty intervention. The unclear risk of bias in omentoplasty studies was due to the lack of allocation concealment in one study decreased the quality of evidence by one level. The large magnitude of effect in the omentoplasty studies increased the quality of evidence by one level. There was a moderate quality of evidence for $\mathrm{AL}$ in the early NG tube removal (or no NG tube) intervention. The high risk of bias due to both the lack of randomization and allocation concealment in all studies decreased the quality of evidence by two levels. The large magnitude of effect increased the quality of evidence by one level. There was a very low quality of evidence for AL in the stapled anastomosis intervention. The high risk of bias due to both the lack of randomization and allocation concealment in nearly all studies decreased the quality of evidence by two levels. The imprecision of the measure of effect due to the lack of statistical significance reduced the quality of evidence by one level. The moderate level of heterogeneity in the pooled estimate decreased the quality of evidence by one level. The evidence profile is summarized according to intervention type in Table 4 (GRADE summarized in Additional file 1: Table S5).

\section{Discussion}

This is the first systematic review and meta-analysis to provide a graded quality of evidence summary all previous RCT interventions aiming to reduce anastomotic leakage (AL) following esophagectomy. Our review findings suggest there is a high quality of evidence to support omentoplasty as an efficacious intervention 


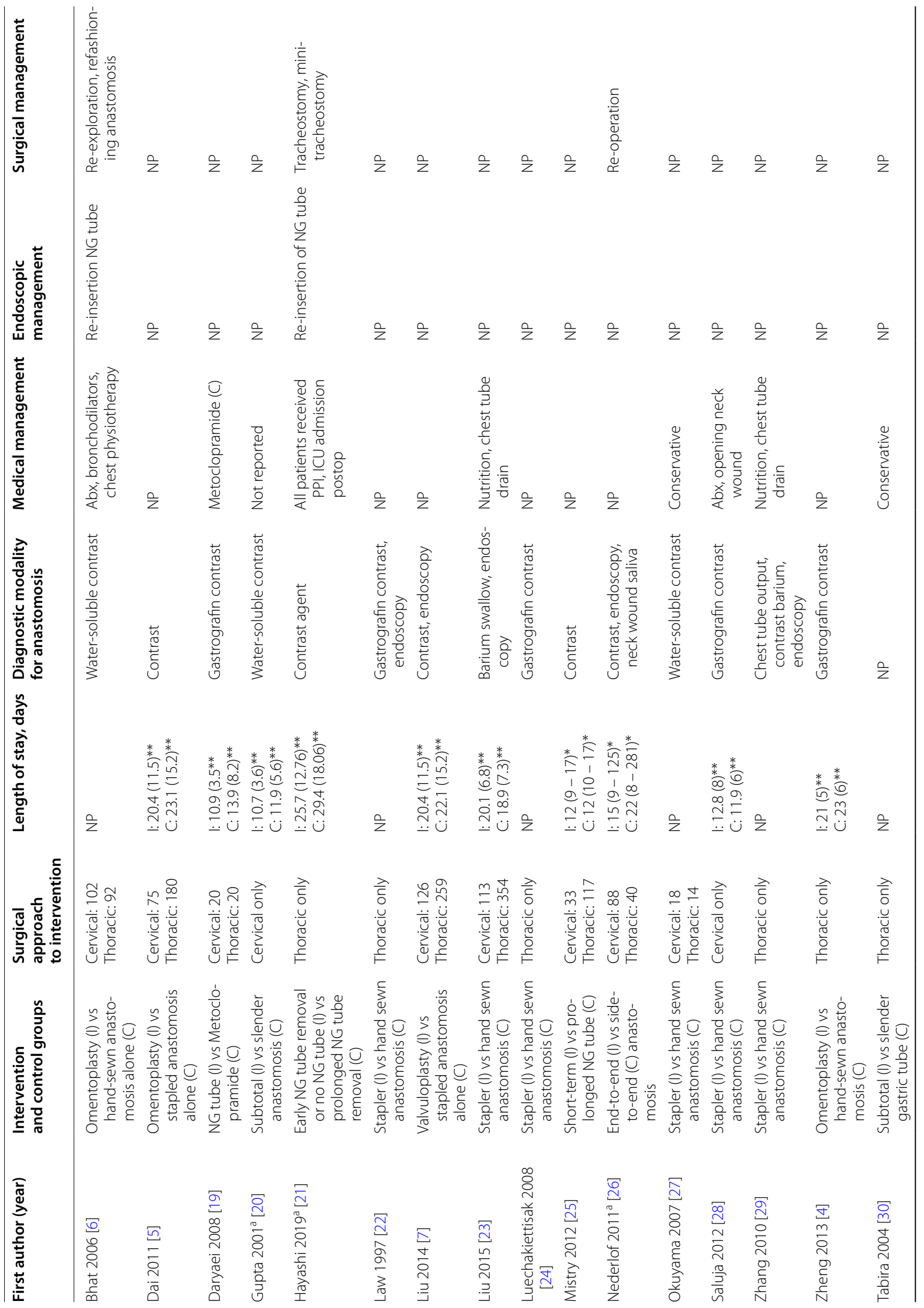




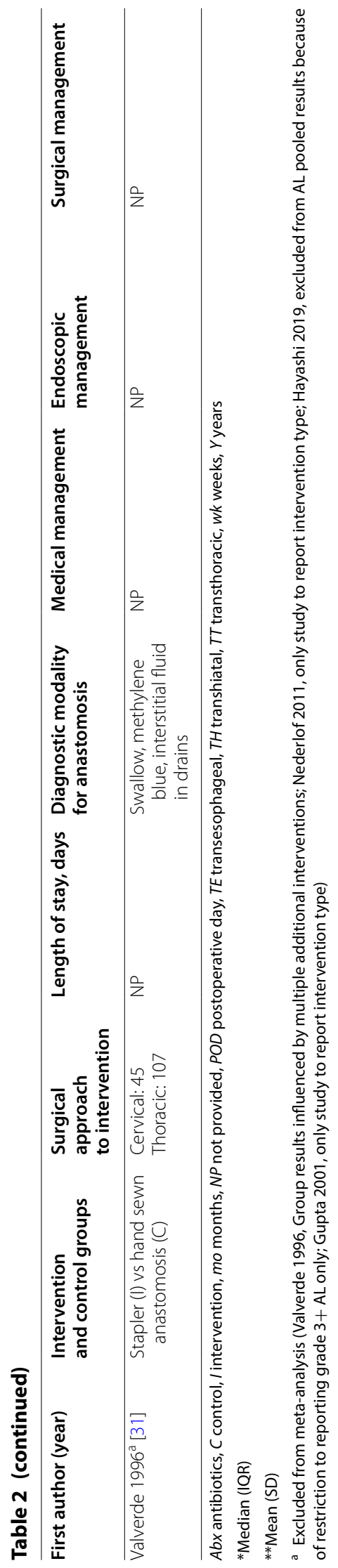




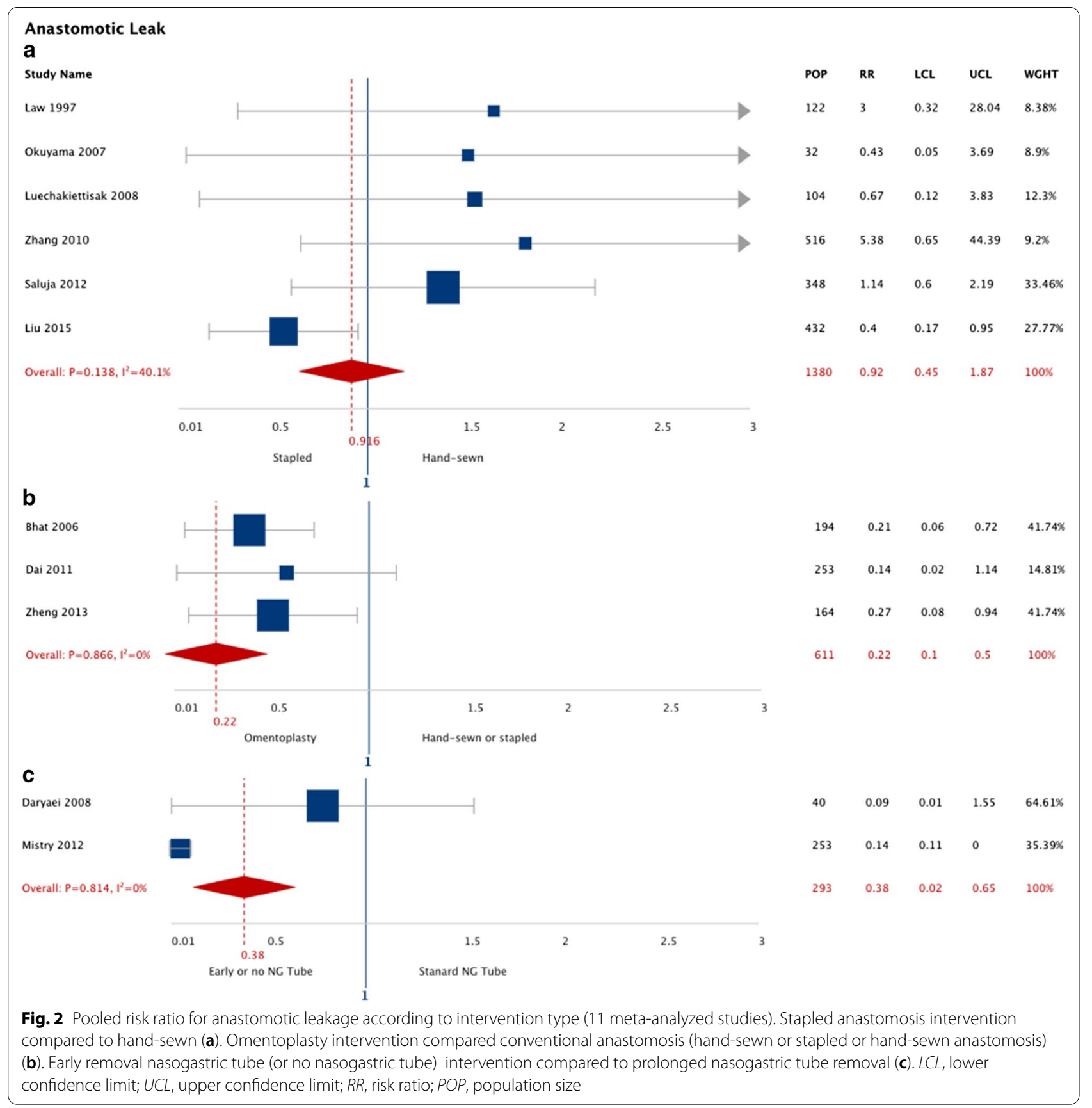

to significantly reduce the risk of AL; the perceived benefit that omentoplasty enhances wound healing through increased perfusion to the surgical site offers further justification to this finding [20,30,31]. Our findings also showed that omentoplasty lowered the risk of anastomotic stricture, mortality, and length of stay in hospital following esophageal cancer resection, albeit not statistically significantly. The early NG tube removal (or no NG tube) intervention showed a significant reduction in the risk of $\mathrm{AL}$ when compared to prolonged NG tube removal, but the moderate quality of evidence for this finding indicates the need for further research. There was a small difference in risk of AL for stapled vs. hand-sewn anastomosis that was not statistically significant and the quality of evidence was very low.

In the present review, subgroup analysis suggested that omentoplasty led to a greater reduction in risk of $\mathrm{AL}$ after esophagectomy with a thoracic 
Table 3 Risk ratios for anastomotic leak for omentoplasty intervention (subgroup by cervical or thoracic approach)

\begin{tabular}{|c|c|c|c|c|}
\hline Group & $\begin{array}{l}\text { Study (Author, } \\
\text { year) }\end{array}$ & Risk ratio & $\begin{array}{l}95 \% \mathrm{Cl} \text { (lower, } \\
\text { upper) }\end{array}$ & $1^{2}$ \\
\hline \multirow[t]{3}{*}{ Cervical* } & Bhat $2006^{6}$ & 0.22 & $0.080,0.88^{*}$ & - \\
\hline & Dai $2011^{5}$ & 0.26 & $0.030,2.08$ & - \\
\hline & $\begin{array}{l}\text { Overall ( } n=2 \text { stud- } \\
\text { ies) }\end{array}$ & 0.23 & $0.080,0.88^{*}$ & 0 \\
\hline \multirow[t]{3}{*}{ Thoracic* } & Bhat $2006^{6}$ & 0.19 & $0.020,1.52$ & - \\
\hline & Dai $2011^{5}$ & 0.18 & $0.010,3.68$ & - \\
\hline & $\begin{array}{l}\text { Overall ( } \mathrm{n}=2 \text { stud- } \\
\text { ies) }\end{array}$ & 0.19 & $0.030,1.03$ & 0 \\
\hline
\end{tabular}

*Omentoplasty vs. conventional anastomosis (stapled or hand-sewn anastomosis)

anastomosis (transthoracic or Ivor Lewis surgery) compared to cervical anastomosis (transhiatal surgery); but this finding should be interpreted with caution due to the low number of omentoplasty studies reviewed.
This finding that the esophagectomy anastomosis location has an association with the incidence of $\mathrm{AL}$ is consistent with previous literature. Studies have shown that patients who undergo transhiatal surgery have a higher incidence of AL compared to transthoracic surgery. However, the possible mechanism(s) explaining this phenomenon remains somewhat controversial $[4,18]$. Some studies have attempted to better elucidate the underlying mechanisms. In two previous meta-analyses, the incidence of $\mathrm{AL}$ among patients treated with transhiatal esophagectomy was significantly greater compared to patients treated with transthoracic esophagectomy [30, 32]. Another hypothesis proposes that cervical anastomoses may have higher rates of AL due to perfusion issues of the gastric conduit reaching the neck. The latter is supported by the well-established understanding that perfusion and oxygen delivery to the site of wound healing after surgical resection has a substantial influence on the integrity of the wound healing process [30-32].

There is a need for further research and improved reporting in future studies to allow for elucidation of

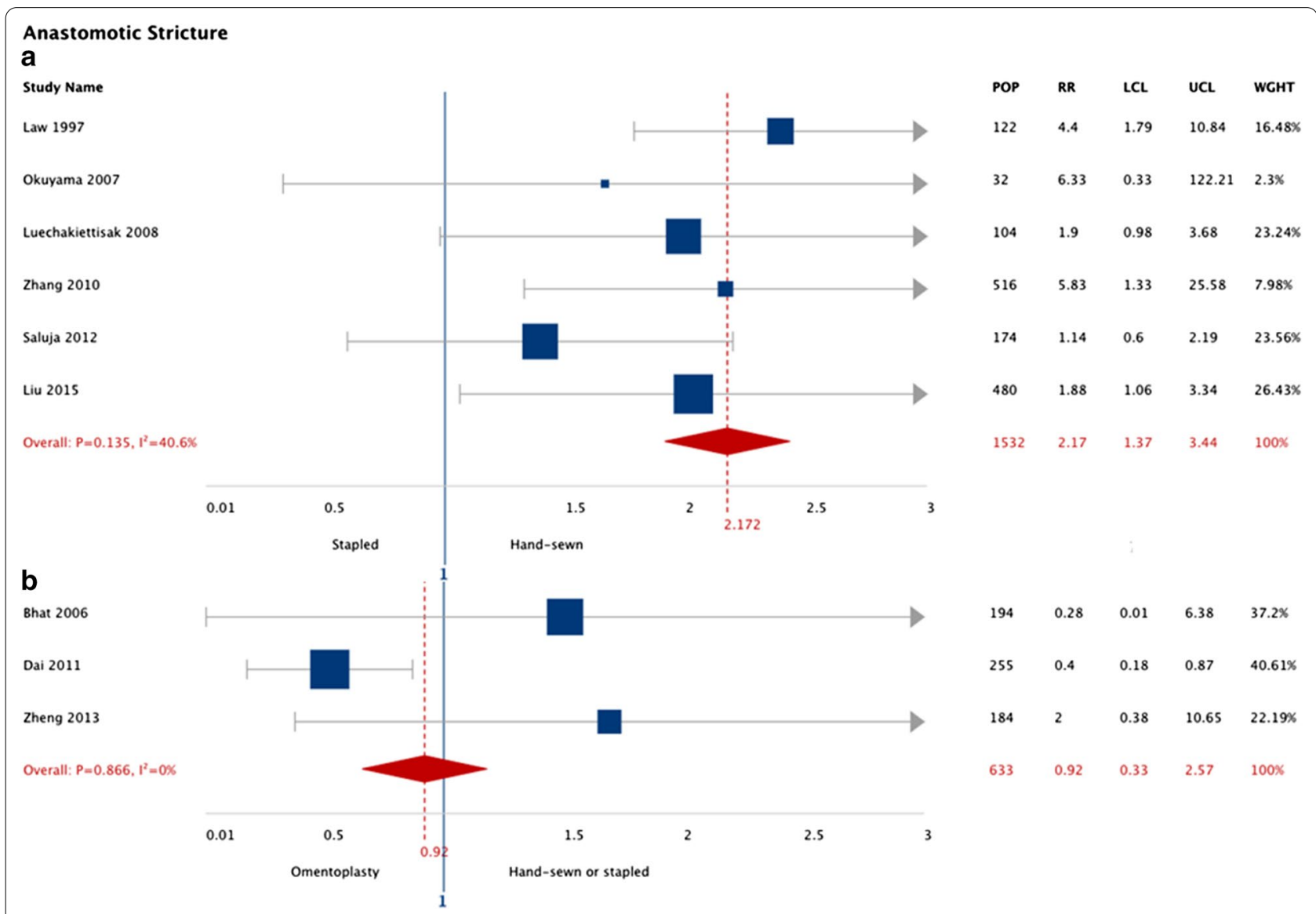

Fig. 3 Pooled risk ratio for anastomotic stricture grouped according to intervention type (11 meta-analyzed studies). Stapled anastomosis intervention compared to hand-sewn (a). Omentoplasty intervention compared to conventional anastomosis (stapled or hand-sewn anastomosis) (b). $L C L$, lower confidence limit; $U C L$, upper confidence limit; $R R$, risk ratio; $P O P$, population size 


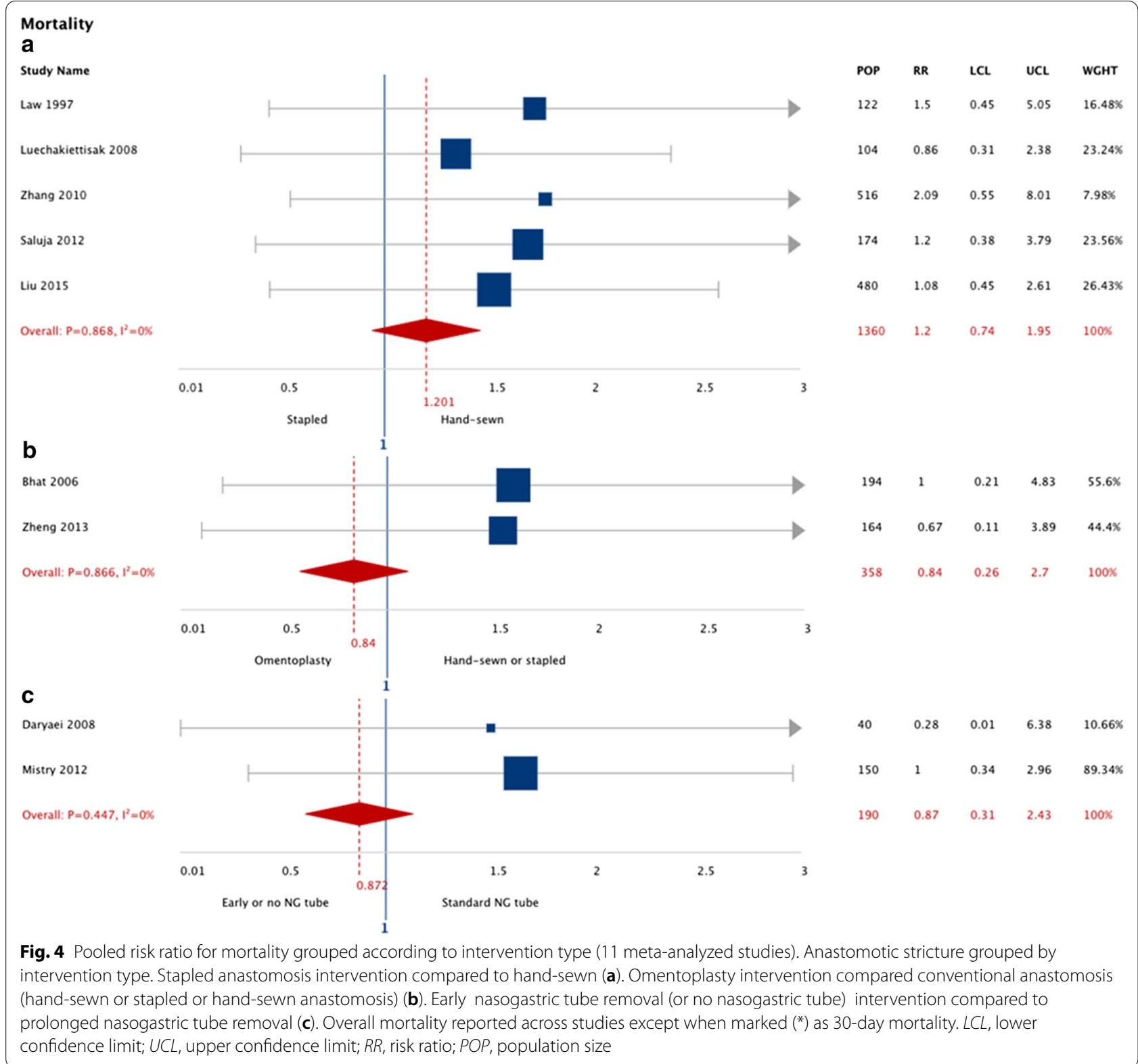

possible differences in intervention groups. The paucity of studies surrounding the investigation of early NG tube removal (or no NG tube), subtotal gastric reconstruction intervention (vs. a slender tube), and other techniques such as valvuloplasty may reflect the need for further research to better understand the role of these interventions in the prevention of AL. Another limitation in our meta-analysis of omentoplasty studies is that the comparison group included both stapled and hand-sewn anastomosis. However, the risk of AL among omentoplasty studies was not significantly different when subgrouped by stapled vs. hand-sewn anastomosis. Thus, we do not anticipate this limitation to influence our conclusions. Finally, it was not possible to obtain data from the included studies to allow for subgroup analysis according to the use of adjuvant radiation and/or chemotherapy.

Our review identified some gaps in the literature that may be better understood with further research. The lack of reported measures of quality of life or psychometric outcomes was one area where further exploration may be beneficial. The patient-reported outcomes may allow us to better understand key aspects of patient experience to improve the quality of care around the delivery of interventions. Another barrier was the lack of RCT studies performed in North America, which means 
Random sequence generation (selection bias)

Allocation concealment (selection bias)

Blinding of participants and researchers (performance bias)

Blinding of outcome assessment (detection bias)

Incomplete outcome data (attrition bias)

Selective reporting (reporting bias)

Publication bias

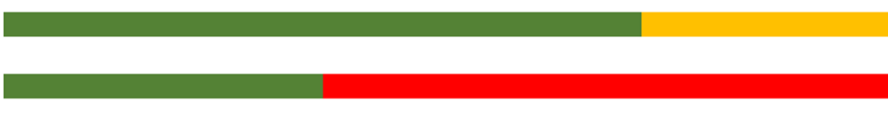

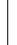




\section{Supplementary Information}

The online version contains supplementary material available at https://doi. org/10.1186/s12893-020-01026-w.

Additional file 1: Literature search strategy. Table S2. Descriptive risk ratio results for RCT's excluded from meta-analysis. Table S3. Risk ratios for anastomotic leak among omentoplasty studies (grouped according to stapled or hand-sewn anastomosis comparison groups). Table S4. A revised tool to assess risk of bias in randomized trials (RoB 2). Table S5. Grading of Recommendations, Assessment, Development and Evaluations for Anastomotic Leak.

\section{Abbreviations}

AL: Anastomotic leak; GRADE: Grading of recommendations, assessment, development, and evaluations; IQR: Interquartile range; NG: Nasogastric; PRISMA: Preferred reporting in systematic reviews and meta-analysis; RCT: Randomized controlled trial; RR: Risk ratio; TE: Transesophageal; TH: Transhiatal; TT:Transthoracic; WMD: Weighted mean difference.

\section{Acknowledgements}

Not applicable.

\section{Authors' contributions}

Concept and design: EG, DM, DF, AS. Acquisition of data: SK, EG. Analysis or interpretation of data: $S K, E G, D M, D F, A S$. Drafting of the manuscript: EG. Critical revision of the manuscript: All authors. Statistical analysis: EG. Administrative, technical, or material support: All authors. Supervision: DM, AS. Ms. Grigor had full access to all the data in the study and takes full responsibility for the integrity of the data and the accuracy of the data analysis. All authors have read and approved the manuscript.

\section{Funding}

No funding was received.

\section{Availability of data and materials}

The dataset generated and analysed in our review are available from the corresponding author on reasonable request.

\section{Ethics approval and consent to participate}

Not applicable.

\section{Consent for publication}

Not applicable.

\section{Competing interests}

The authors declare that they have no competing interests.

\section{Author details}

${ }^{1}$ Department of Surgery, Division of Thoracic Surgery, The Ottawa Hospital, 501 Smyth Road, PO Box 201B, Ottawa, ON K1H 8L6, Canada. ${ }^{2}$ Clinical Epidemiology Program, Ottawa Hospital Research Institute, Ottawa, Canada.

${ }^{3}$ Faculty of Medicine, University of Ottawa, Ottawa, Canada.

Received: 27 August 2020 Accepted: 20 December 2020 Published online: 18 January 2021

\section{References}

1. Low ED, Kuppusamy KM, Alderson CD, Cecconello BI, Chang SA, Darling $\mathrm{MG}$, et al. Benchmarking complications associated with esophagectomy. Ann Surg. 2019;269(2):291-8.

2. Tabatabai A, Hashemi M, Mohajeri G, Ahmadinejad M, Khan I, Haghdani S. Incidence and risk factors predisposing anastomotic leak after transhiatal esophagectomy (original article)(clinical report). Ann Thorac Med. 2009;4(4):197-200.
3. Markar S, Arya R, Karthikesalingam S, Hanna A. Technical factors that affect anastomotic integrity following esophagectomy: systematic review and meta-analysis. Ann Surg Oncol. 2013;20(13):4274-81.

4. Zheng Q, Wang J, Ying M, Liu S. Omentoplasty in preventing anastomotic leakage of oesophagogastrostomy following radical oesophagectomy with three-field lymphadenectomy. Eur J Cardio-Thorac Surg. 2013;43(2):274-8.

5. Dai J, Zhang Z, Min J, Huang X, Wang J. Wrapping of the omental pedicle flap around esophagogastric anastomosis after esophagectomy for esophageal cancer. Surgery. 2011;149(3):404-10.

6. Bhat MA, Dar MA, Lone GN, Dar AM. Use of pedicled omentum in esophagogastric anastomosis for prevention of anastomotic leak. Ann Thorac Surg. 2006;82(5):1857-62.

7. Liu Q, Deng X, Wang J, Hou B, Li J, Min J, et al. Use of oesophageal flap valvuloplasty and wrapping suturing technique in preventing postoperative complications after oesophagectomy for oesophageal cancer. Eur J Surg Oncol. 2014;40(10):1355-60.

8. Chen L, Liu F, Wang K, Zou W. Omentoplasty in the prevention of anastomotic leakage after oesophagectomy: a meta-analysis. Eur J Surg Oncol. 2014;40(12):1635-40

9. Yuan Y, Zeng X, Hu Y, Xie T, Zhao Y. Omentoplasty for oesophagogastrostomy after oesophagectomy. Cochrane Database Syst Rev. 2014. https:// doi.org/10.1002/14651858.CD008446.pub3.

10. Vetter D, Gutschow C. Strategies to prevent anastomotic leakage after esophagectomy and gastric conduit reconstruction. Langenbeck's Arch Surg. 2020. https://doi.org/10.1007/s00423-020-01926-8.

11. Weijs T, Kumagai K, Berkelmans G, Nieuwenhuijzen G, Nilsson M, Luyer M. NG decompression following esophagectomy: a systematic literature review and meta-analysis. Dis Esophagus. 2017;30(3):1-8.

12. Beitler AL, Urschel JD. Comparison of stapled and hand-sewn esophagogastric anastomoses. Am J Surg. 1998;175(4):337-40.

13. Guyatt GH, Oxman AD, Vist GE, Kunz R, Falck-Ytter Y, Alonso-Coello P, et al. GRADE: an emerging consensus on rating quality of evidence and strength of recommendations. BMJ. 2008;336:924-6.

14. Moher $D$, et al. Preferred reporting items for systematic reviews and meta-analyses: the PRISMA statement. Ann Intern Med. 2009;151(4):2649. https://doi.org/10.7326/0003-4819-151-4-200908180-00135.

15. Hariton E, Locascio J. Randomised controlled trials —-the gold standard for effectiveness research. BJOG Int J Obstetr Gynaecol. 2018;125(13):1716-1716.

16. Fergusson D, Laupacis A, Salmi L, Mcalister F, Huet C, Fergusson D. What should be included in meta-analyses? An exploration of methodological issues using the ISPOT meta-analyses. Int J Technol Assess Health Care. 2000;16(04):1109-19.

17. Mistry R, Vijayabhaskar R, Karimundackal G, Jiwnani S, Pramesh C. Effect of short-term vs prolonged NG decompression on major postesophagectomy complications: a parallel-group, randomized trial. Arch Surg. 2012;147(8):747-51.

18. Gooszen J, Goense L, Gisbertz S, Ruurda J, Van Hillegersberg R, Van Berge HM. Intrathoracic versus cervical anastomosis and predictors of anastomotic leakage after oesophagectomy for cancer. Br J Surg. 2018;105(5):552-60. https://doi.org/10.1002/bjs.10728.

19. Daryaei P, Vaghef DF, Mir M, Harirchi I, Salmasian H. Omission of NG tube application in postoperative care of esophagectomy. World J Surg. 2009:33(4):773-7.

20. Gupta NM, Gupta RR, Manikyam S, Gupta V. Minimizing cervical esophageal anastomotic complications by a modified technique. Am J Surg. 2001;181(6):534-9.

21. Hayashi M, Kawakubo H, Shoji Y, Mayanagi S, Nakamura R, Suda K, et al. Analysis of the effect of early versus conventional NG tube removal on postoperative complications after transthoracic esophagectomy: a single-center, randomized controlled trial. World J Surg. 2019:43(2):580-9.

22. Law S, Fok M, Chu K, Wong J. Comparison of hand-sewn and stapled esophagogastric anastomosis after esophageal resection for cancer: a prospective randomized controlled trial. Ann Surg. 1997;226(2):169-73.

23. Liu Q, Qiu Y, Deng X, Min J, Dai J. Comparison of outcomes following endto-end hand-sewn and mechanical oesophagogastric anastomosis after oesophagectomy for carcinoma: a prospective randomized controlled trial. Eur J Cardio-Thorac Surg. 2015;47(3):e118-23. 
24. Luechakiettisak P, Kasetsunthom S. Comparison of hand-sewn and stapled in esophagogastric anastomosis after esophageal cancer resection: a prospective randomized study. J Med Assoc Thai. 2008;91(5):681-5.

25. Nederlof NW, Tilanus HK, Tran TJ, Hop WL, Wijnhoven B, De Jonge J. End-to-end versus end-to-side esophagogastrostomy after esophageal cancer resection: a prospective randomized study. Ann Surg. 2011;254(2):226-33.

26. Okuyama M, Motoyama S, Suzuki H, Saito R, Maruyama K, Ogawa J. Handsewn cervical anastomosis versus stapled intrathoracic anastomosis after esophagectomy for middle or lower thoracic esophageal cancer: a prospective randomized controlled study. Surg Today. 2007:37(11):947-52.

27. Saluja S, Ray S, Pal S, Sanyal S, Agrawal N, Dash N, et al. randomized trial comparing side-to-side stapled and hand-sewn esophagogastric anastomosis in neck. J Gastrointest Surg. 2012;16(7):1287-95.

28. Zhang Y, Gao B, Wang H, Su Y, Yang Y, Zhang J, et al. Comparison of anastomotic leakage and stricture formation following layered and stapler oesophagogastric anastomosis for cancer: a prospective randomized controlled trial. J Int Med Res. 2010;38(1):227-33.
29. Tabira Y, Sakaguchi T, Kuhara H, Teshima K, Tanaka M, Kawasuji M. The width of a gastric tube has no impact on outcome after esophagectomy (Scientific papers). Am J Surg. 2004;187(3):417-21.

30. Hulscher JB, Tijssen JG, Obertop H, van Lanschot JJ. Transthoracic versus transhiatal resection for carcinoma of the esophagus: a meta-analysis. Ann Thorac Surg. 2001;72(1):306-13.

31. Chadi S, Fingerhut A, Berho M, DeMeester S, Fleshman J, Hyman N, et al. Emerging trends in the etiology, prevention, and treatment of gastrointestinal anastomotic leakage. J Gastrointest Surg. 2016;20(12):2035-51.

32. Rindani R, Martin CJ, Cox MR. Transhiatal versus Ivor-Lewis oesophagectomy: is there a difference? Aust N Zeal J Surg. 1999;69(3): 187-194.http:// search.proquest.com/docview/69617458/.

\section{Publisher's Note}

Springer Nature remains neutral with regard to jurisdictional claims in published maps and institutional affiliations.
Ready to submit your research? Choose BMC and benefit from:

- fast, convenient online submission

- thorough peer review by experienced researchers in your field

- rapid publication on acceptance

- support for research data, including large and complex data types

- gold Open Access which fosters wider collaboration and increased citations

- maximum visibility for your research: over $100 \mathrm{M}$ website views per year

At BMC, research is always in progress.

Learn more biomedcentral.com/submissions 